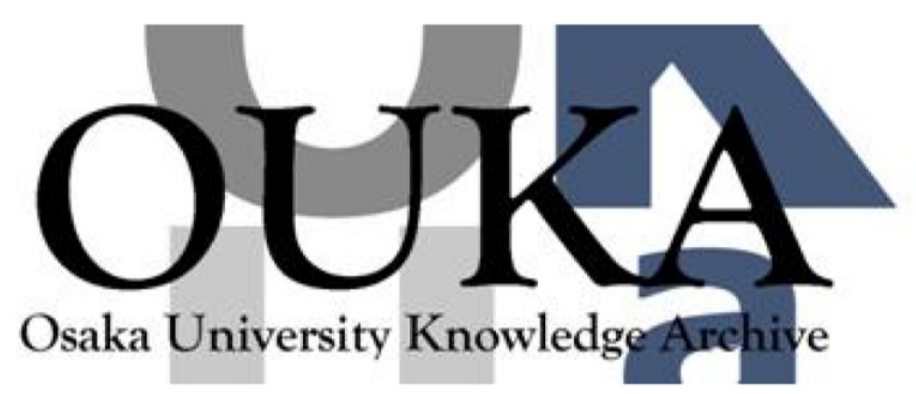

\begin{tabular}{|c|c|}
\hline Title & $\begin{array}{l}\text { Main-Chain Stiffness and Helical Conformation } \\
\text { of a Poly (quinoxaline-2,3-diyl) in Solution }\end{array}$ \\
\hline Author (s) & $\begin{array}{l}\text { Nagata, Yuuya; Hasegawa, Hirokazu; Terao, Ken } \\
\text { et al. }\end{array}$ \\
\hline Citation & Macromolecules. 48(21) p. 7983-p. 7989 \\
\hline Issue Date & $2015-10-26$ \\
\hline oaire:version & AM \\
\hline URL & https://hdl. handle. net/11094/81806 \\
\hline rights & $\begin{array}{l}\text { This document is the Accepted Manuscript } \\
\text { version of a Published Work that appeared in } \\
\text { final form in Macromolecules, } \odot \text { American } \\
\text { Chemical Society after peer review and } \\
\text { technical editing by the publisher. To access } \\
\text { the final edited and published work see } \\
\text { https://doi.org/10.1021/acs. macromol. } 5 \text { b01919. }\end{array}$ \\
\hline Note & \\
\hline
\end{tabular}

Osaka University Knowledge Archive : OUKA

https://ir. Library. osaka-u. ac. jp/

Osaka University 


\title{
Main-Chain Stiffness and Helical Conformation of a Poly(quinoxaline-2,3-diyl) in Solution
}

\author{
Yuuya Nagata, ${ }^{\dagger, \perp}$ Hirokazu Hasegawa,,,,$+ \perp$ Ken Terao, $, *, *$ and Michinori Suginome ${ }^{\dagger, \|}$ \\ 'Department of Synthetic Chemistry and Biological Chemistry, Graduate School of Engineering, \\ Kyoto University, Kyoto 606-8501, Japan, ${ }^{7}$ Department of Macromolecular Science, Graduate \\ School of Science, Osaka University, 1-1 Machikaneyama-cho, Toyonaka, Osaka, 560-0043, \\ Japan, ${ }^{\S}$ Materials Characterization Laboratories, Toray Research Center, Inc., 3-3-7, \\ Sonoyama, Otsu, Shiga 520-8567, Japan, "CREST, Japan Science and Technology Agency (JST), \\ Katsura, Nishikyo-ku, Kyoto 615-8510, Japan
}

(Running Title: Chain Stiffness of a Polyquinoxaline in Solution)

*Corresponding author: e-mail kterao@chem.sci.osaka-u.ac.jp.

${ }^{\perp}$ These authors equally contributed to the paper.

ABSTRACT: Light and small-angle X-ray scattering and viscosity measurements in tetrahydrofuran at $25^{\circ} \mathrm{C}$ were made for nine helical poly[5,8-dimethyl-6,7bis(propoxymethyl)quinoxaline-2,3-diyl] samples ranging in the weight-average molar mass $M_{\mathrm{w}}$ from $8 \times 10^{3} \mathrm{~g} \mathrm{~mol}^{-1}$ to $6 \times 10^{5} \mathrm{~g} \mathrm{~mol}^{-1}$ to determine the particle scattering function, the radius of gyration, and the intrinsic viscosity as a function of $M_{\mathrm{w}}$. The dimensional and hydrodynamic properties were consistently explained in terms of the Kratky-Porod wormlike chain. The helix pitch per residue $h$ (or the contour length per residue) and the chain stiffness parameter $\lambda^{-1}$ (the Kuhn segment length or twice of the persistence length) were estimated to be $h=0.19 \mathrm{~nm}$ and $\lambda^{-1}=43 \pm 3 \mathrm{~nm}$. The former parameter corresponds to an internal rotation angle of about $120^{\circ}$ which is substantially the same as the most stable helical structure estimated from the internal rotation potential. The latter one $\left(\lambda^{-1}\right)$ indicates that the poly(quinoxaline-2,3-diyl) has rigid helical main chain of which the dihedral angle between adjacent monomer units are restricted by steric hindrance.

\section{Introduction}

Helical polymers ${ }^{1-6}$ have attracted considerable attention because of their unique macromolecular functions leading to chiral separation, ${ }^{7-9}$ asymmetric catalysis, ${ }^{10-11}$ and chiroptical materials. ${ }^{12-16}$ To gain deeper insight into their intriguing macromolecular functions, it is particularly important to determine their conformations in dilute solution. So far, physical properties of helical polymers such as polysilanes, ${ }^{17-18}$ polyacetylenes, ${ }^{19}$ polyisocyanates, ${ }^{20-21}$ polyisocyanides, ${ }^{22}$ and polysaccharide derivatives ${ }^{23-27}$ have been investigated in dilute solution to reveal their intrinsic properties arising from their helical structure.

Poly(quinoxaline-2,3-diyl)s (PQXs) are a unique class of synthetic helical polymers prepared by living polymerization of 1,2-diisocyanobenzenes with transition metal initiators. ${ }^{28-31}$ PQXs have been supposed to adopt rigid helical structure in solution owing to the steric repulsion of the two substituents at the 5- and 8-positions on the quinoxaline ring. ${ }^{28,32}$ Recently, we reported that single-handed PQXs bearing diarylphosphino groups can serve as highly effective chiral ligands 
for transition metal catalysts in asymmetric reactions. ${ }^{33}$ Furthermore, we also reported solventdependent helix inversion of PQXs bearing chiral side chains, ${ }^{34-35}$ which enables the highly enantioselective production of both enantiomers from a single chiral catalyst in various asymmetric reactions. ${ }^{36-39}$ This feature could also be extended to the formation of chiralityswitchable cholesteric superstructures ${ }^{40}$ and generation of handedness-switchable circularly polarized luminescence. ${ }^{41}$ It should be noted that the rigidity of the polymer main chain plays important roles in these application of PQXs. For instance, a chiral ligand should have a rigid molecular framework to exhibit high enantioselectivity. The chirality-switchable cholesteric materials are also based on the rigid main chain to stabilize the liquid crystalline state. Furthermore, a rigid, chiral, and fluorescent molecular framework is indispensable to exhibit circularly polarized luminescence with high dissymmetry factor. However, it is still difficult to predict the chain stiffness properly only from the chemical structure of semiflexible or rigid polymers because it is determined by rather small fluctuation of the internal rotation and the bond angle.

In order to develop new chiral functional materials based on PQXs, the comprehension of dimensional and hydrodynamic properties of PQXs in dilute solution is thus significantly important. These properties are characterized mainly by the contour length and the chain stiffness parameter $\lambda^{-1}$ (the Kuhn segment length or twice the persistence length) in terms of the KratkyPorod wormlike chain ${ }^{42}$ (or more generally, the helical wormlike chain). ${ }^{43-44}$ Firstly, the contour length is related to the helical structure of the polymer in solution. Although two helical conformations having different helix pitches were proposed for PQXs, ${ }^{29}$ we can make it clear through the determination of the contour length of PQXs. Secondary, the chain stiffness parameter is decisively related with solution properties, that is, not only solution viscosity including concentrated solutions ${ }^{45-46}$ but also liquid crystallinity. ${ }^{45}$

In this paper, our research interest has focused on the chain stiffness and the helix pitch (or helix rise) per residue of poly[5,8-dimethyl-6,7-bis(propoxymethyl)quinoxaline-2,3-diyl], which is the simplest class of PQXs and has been studied in detail in these two decades. ${ }^{47}$ We studied dimensional and hydrodynamic properties of PQXs in tetrahydrofuran (THF) by a size exclusion chromatography (SEC) equipped with a multi-angle laser light scattering (MALS) photometer and a twin capillary viscometer detector and by synchrotron radiation small-angle X-ray scattering (SAXS) measurements.

\section{Experimental Section}

Sample Preparation. Eight poly[5,8-dimethyl-6,7-bis(propoxymethyl)quinoxaline-2,3-diyl] samples PQ- $\boldsymbol{n}$ of which degree of polymerization $n$ ranges between 20 and 1000 were synthesized by living polymerizations of monomer $\mathbf{1}^{47}$ in the presence of an organonickel complex ${ }^{48}$ (Scheme $1)$. Their dispersity $(Ð)$ defined as the ratio of weight- to number-average molar masses $M_{\mathrm{w}} / M_{\mathrm{n}}$ were between 1.01 and 1.07 determined by the size exclusion chromatography described below. A high molar mass sample PQ-high with relatively broad $Ð\left(M_{\mathrm{w}} / M_{\mathrm{n}}=1.33\right)$ was prepared by using a simple nickel(II) complex, $\mathrm{NiCl}_{2}\left(\mathrm{PMe}_{3}\right)_{2}$, as reported before. ${ }^{49}$ These polymerization proceeded quickly at room temperature and gave corresponding polymers in quantitative yields. 


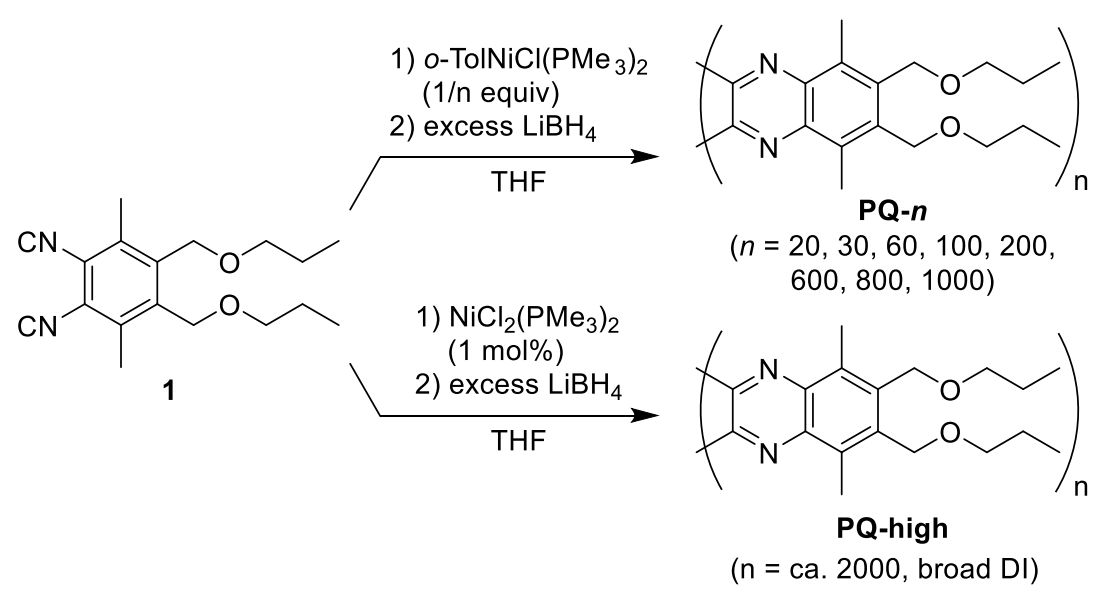

Scheme 1. Polymerization of 1,2-dicyanobenzene monomer 1 with nickel initiators.

Static Light Scattering (SLS) and Viscosity Measurements with Size Exclusion Chromatography (SEC). SLS and viscosity measurements for all samples in THF were made using SEC equipped with a DAWN HELEOS multi-angle laser light scattering photometer with a He-Ne laser of which wavelength $\lambda_{0}$ in vacuum was $658 \mathrm{~nm}$, a VISCOSTAR-II online differential viscometer, and an Optilab rEX differential refractometer (all detectors supplied by Wyatt Technology, USA). These methods are widely used to characterize various polymers in solution including linear and branched polystyrenes and a polysaccharide derivative. ${ }^{26,50-52}$ A SEC system consisting of a LC-20AD isocratic pump, a SIL-20A autosampler supplied by SHIMADZU, Japan, and above mentioned detectors were used with three TSKgel GMHXL columns (TOSOH, Japan) for PQ-20, PQ-30, ..., and PQ-200, with a $\mathrm{GMH}_{\mathrm{HR}}-\mathrm{H}$ column and two $\mathrm{GMH}_{\mathrm{XL}}$ columns for PQ600, PQ-800, and PQ-1000, or with two GMHXL and a G2500HXL columns for PQ-high. The flow rate was set to $1.0 \mathrm{~cm}^{3} \mathrm{~min}^{-1}$, the column and detector temperature were kept at room temperature (substantially the same as $25^{\circ} \mathrm{C}$ ), and the injection volume was $0.2 \mathrm{~cm}^{3}$. The ASTRA software (ver.5.3.3, Wyatt technology, USA) was used to collect and to analyze the data. Differential refractive index increment $\partial n / \partial c$ for PQ-600, PQ-800, PQ-1000, and PQ-high in THF was determined by using the peak area of the refractive index chromatogram and the polymer mass concentration $c$ of injected solution assuming full recovery. The $\partial n / \partial c$ value was determined to be $0.196 \mathrm{~cm}^{3} \mathrm{~g}^{-1}$ at $\lambda_{0}=658 \mathrm{~nm}$. Angular dependence of the scattering intensity was analyzed using the Berry square-root $\mathrm{plot}^{53}$ in a scattering angle range from $45.8^{\circ}$ to $138.8^{\circ}$ to estimate the weight-average molar mass $M_{\mathrm{w}}$ and the $z$-average mean-square radius of gyration $\left\langle S^{2}\right\rangle_{\mathrm{z}}$ of each fraction. It should be noted that the second virial term does not cause an appreciable error in $M_{\mathrm{w}}$ (and $\left\langle S^{2}\right\rangle_{\mathrm{z}}$ ) if we assume the second virial coefficient estimated from SAXS measurements described below. To verify the obtained $M_{\mathrm{w}}$, the universal calibration method was examined for all PQ- $\boldsymbol{n}$ samples with polystyrene standard (Tosoh, Japan) of which $M_{\mathrm{w}}$ ranges from $1.02 \times 10^{4}$ to $8.42 \times 10^{6}$. The resultant $M_{\mathrm{w}}$ values from the two methods agree with each other within $\pm 2 \%$. The SEC chromatograms have shoulder peaks suggesting high molar mass components except for low molar mass samples as displayed in Figure 1. The shoulder peaks were omitted in the discussion of dimensional and hydrodynamic properties described below. 


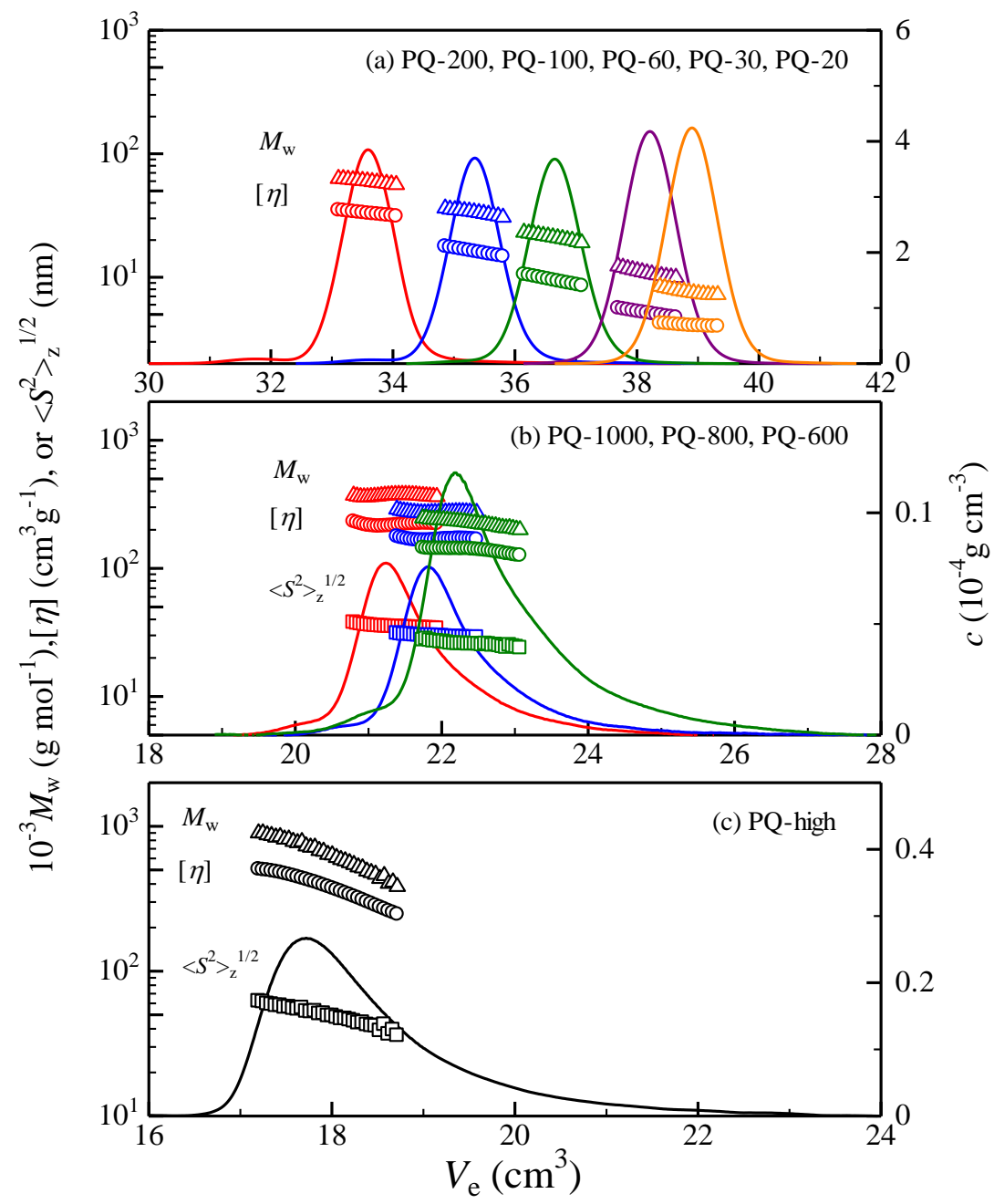

Figure 1. Retention volume $V_{\mathrm{e}}$ of the weight-average molar mass $M_{\mathrm{w}}$ (triangles), the $z$-average radius of gyration $\left\langle S^{2}\right\rangle_{\mathrm{z}}{ }^{1 / 2}$ (squares), the intrinsic viscosity [ $\left.\eta\right]$ (circles) and polymer mass concentration $c$ (solid curves) in THF.

Small angle X-ray Scattering (SAXS). Synchrotron radiation SAXS experiments for PQ20, PQ-30, PQ-60, PQ-100, and PQ-200 in THF at $25^{\circ} \mathrm{C}$ were carried out at the BL-10C beamline in KEK-PF (Ibaraki, Japan). The camera length, $\lambda_{0}$, and the accumulation time were set to be 980 $\mathrm{mm}, 0.1488 \mathrm{~nm}$, and $300 \mathrm{sec}$, respectively. The scattered light was detected by a PILATUS3$300 \mathrm{KW}$ hybrid photon counting detector (DECTRIS, Switzerland). Silver behenate was used to determine the beam center and the camera length. The circular average method was utilized to determine the scattering intensity $I(q)$ as a function of the magnitude $q$ of scattering vector. The excess scattering intensity $\Delta I(q)$ of each solution was determined from the difference between $I(q)$ for the solution and the solvent in the same capillary cell taking intensity and transparency of the incident X-ray into account. Four solutions with different polymer mass concentration $c$ ranging in $3 \times 10^{-3} \mathrm{~g} \mathrm{~cm}^{-3}$ and $1.5 \times 10^{-2} \mathrm{~g} \mathrm{~cm}^{-3}$ was measured to extrapolate $[c / \Delta I(q)]^{1 / 2}$ to infinite dilution. The $P(q)$ as well as $\left\langle S^{2}\right\rangle_{z}$ were determined by means of the extrapolation of $[c / \Delta I(q)]_{c=0}^{1 / 2}$ to zero $q^{2}$. Since the $[c / \Delta I(q)]_{c=0}^{1 / 2}$ data for PQ-100 and PQ-200 were hard to extrapolate to $q^{2}=0$, the $[c / \Delta I(0)]_{c=0}{ }^{1 / 2}$ values were estimated from those for PQ-20, PQ-30, and PQ-60 considering that 
$[c / \Delta I(0)]_{c=0}{ }^{1 / 2}$ should be proportional to $M_{\mathrm{w}}{ }^{-1 / 2}$. The $\left\langle S^{2}\right\rangle_{\mathrm{z}}$ values were determined from the initial slope of the Berry plots as shown in Figure 2. Slight discrepancy between the experimental data and the solid curve for PQ-100 at low- $q$ region might be due to the small amount $(\sim 1 \%)$ of larger molar mass component which was observed in the SEC chromatogram. We note that values of $[c / \Delta I(0)]_{c=0}^{1 / 2}$ increased with increasing concentration and then the second virial coefficients were estimated to be $1.2 \times 10^{-3} \mathrm{~mol} \mathrm{~g}^{-2} \mathrm{~cm}^{3}$ and $3 \times 10^{-4} \mathrm{~mol} \mathrm{~g}^{-2} \mathrm{~cm}^{3}$ for PQ-20 and PQ-200, respectively. Preliminary experiments for PQ- $\boldsymbol{n}$ samples in 1,2-dichloroethane and 1,1,2trichloroethane in which helix inversion was observed ${ }^{34-35}$ were also performed at the BL40B2 beamline in SPring- 8 with the incident light of $0.1 \mathrm{~nm}$ wavelength. There was almost no scattering intensity owing to the very low transparency of the solvents.

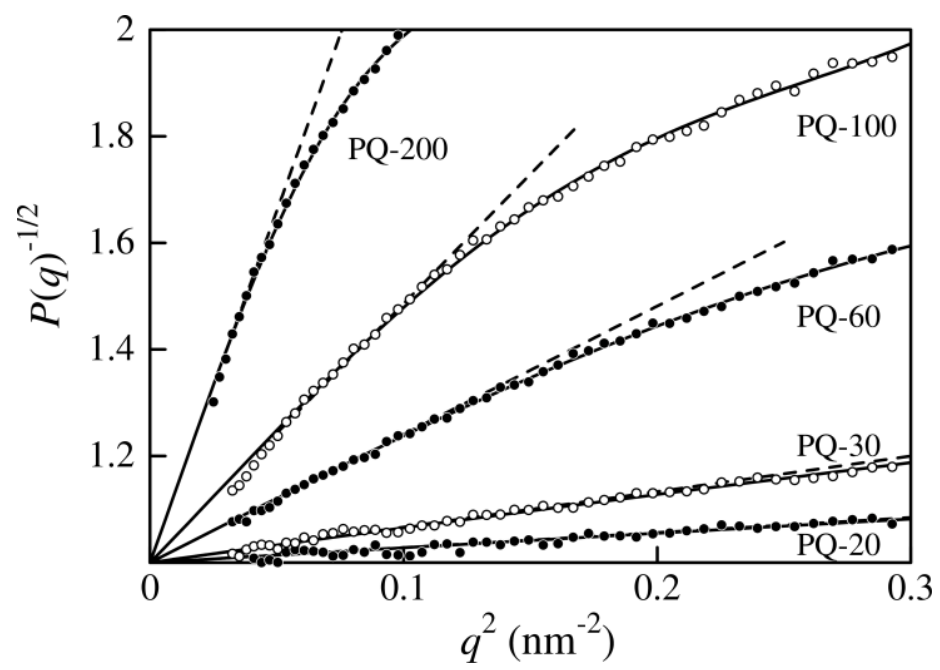

Figure 2. Berry plots for indicated PQ-n samples in THF at $25{ }^{\circ} \mathrm{C}$ at infinite dilution. Dashed lines indicate the initial slopes.

Conformational Calculations. The conformational energy calculations for poly $(5,6,7,8$ tetramethylquinoxaline-2,3-diyl) were carried out by using the method of MOPAC PM6 to estimate internal rotation potential of PQ- $\boldsymbol{n}$. They were performed with MOPAC2012 software ${ }^{54}$ with parameters of PM6 EF GNORM=0.1 GEO-OK. The total energy of quinoxaline 20-mers was calculated by varying the dihedral angle $\phi$, between two adjacent quinoxaline units from $40^{\circ}$ to $140^{\circ}$ with an interval of $5^{\circ}$.

\section{Results and Discussion}

Dimensional and Hydrodynamic Properties. The resultant data for $M_{\mathrm{w}}, M_{\mathrm{w}} / M_{\mathrm{n}},\left\langle S^{2}\right\rangle_{\mathrm{z}}{ }^{1 / 2}$, and the intrinsic viscosity $[\eta]$ in THF at $25^{\circ} \mathrm{C}$ are summarized in Table 1 . The $\left\langle S^{2}\right\rangle_{z}^{1 / 2}$ and $[\eta]$ values were determined by the integration of the peak area of each SEC chromatogram except for PQhigh. The Flory viscosity factor $\Phi$ defined as the following equation

$$
\Phi=\frac{[\eta] M_{\mathrm{w}}}{\left(6\left\langle S^{2}\right\rangle_{\mathrm{z}}\right)^{2 / 3}}
$$


are also listed in Table 1. The $\Phi$ values $\left(1.1 \times 10^{23} \mathrm{~mol}^{-1}\right.$, in average $)$ for higher $M_{\mathrm{w}}$ samples $\left(M_{\mathrm{w}}\right.$ $\left.>2 \times 10^{5} \mathrm{~g} \mathrm{~mol}^{-1}\right)$ are appreciably smaller than those for typical flexible polymers $\left(\sim 2.6 \times 10^{23}\right.$ $\left.\mathrm{mol}^{-1}\right)^{43,55}$ and rather close to that for a typical semiflexible poly $(n$-hexylisocyanate) ( 0.8 to $1.4 \times$ $\left.10^{23} \mathrm{~mol}^{-1}\right),{ }^{56-57}$ indicating the semiflexible nature of the PQ- $\boldsymbol{n}$ in THF.

Table 1. Molecular Characteristics of Poly[5,8-dimethyl-6,7bis(propoxymethyl)quinoxaline-2,3-diyl] Samples and Physical Properties in THF at $25^{\circ} \mathrm{C}$ or Room Temperature

\begin{tabular}{cccccc}
\hline Sample & $M_{\mathrm{w}}\left(10^{-3} \mathrm{~g} \mathrm{~mol}^{-1}\right)^{\mathrm{a}}$ & $M_{\mathrm{w}} / M_{\mathrm{n}}$ & $\left\langle S^{2}\right\rangle_{\mathrm{z}}{ }^{1 / 2}(\mathrm{~nm})$ & {$[\eta]\left(\mathrm{cm}^{3} \mathrm{~g}^{-1}\right)$} & $\Phi\left(10^{23} \mathrm{~mol}^{-1}\right)$ \\
\hline PQ-20 & 7.83 & 1.01 & $1.30^{\mathrm{b}}$ & 4.1 & 9.9 \\
PQ-30 & 11.4 & 1.02 & $2.0^{\mathrm{b}}$ & 5.1 & 4.9 \\
PQ-60 & 21.3 & 1.01 & $3.8^{\mathrm{b}}$ & 9.5 & 2.5 \\
PQ-100 & 34.0 & 1.01 & $5.4^{\mathrm{b}}$ & 16.3 & 2.4 \\
PQ-200 & 59.7 & 1.02 & $8.9^{\mathrm{b}}$ & 33.2 & 1.91 \\
PQ-600 & 227 & 1.07 & $27.3^{\mathrm{c}}$ & 132 & 1.00 \\
PQ-800 & 286 & 1.06 & $31.6^{\mathrm{c}}$ & 167 & 1.03 \\
PQ-1000 & 371 & 1.03 & $36.0^{\mathrm{c}}$ & 219 & 1.18 \\
PQ-high & 574 & 1.33 & $-^{\mathrm{d}}$ & $-^{\mathrm{d}}$ & $-{ }^{\mathrm{d}}$ \\
\hline
\end{tabular}

${ }^{a}$ Average value from the two methods (see text). ${ }^{b}$ From SAXS. ${ }^{c}$ From Light scattering. ${ }^{c}$ Not determined.

Figure 3 illustrates reduced Holtzer plots for PQ-200, PQ-100, PQ-60, PQ-30, and PQ-20 determined by SAXS. Data points are mostly flat except for the low- $q$ region indicating that the stiff main chain and weak contribution from the chain cross-section. Indeed, if we estimate the chain diameter $d$ from the cross sectional plots of $\left[\ln q P(q)\right.$ vs $\left.q^{2}\right]$ on the basis of the equation $[P(q)$ $\left.=P_{0}(q) \exp \left(-k^{2} d^{2} / 16\right)\right],{ }^{58}$ the $d$ value was evaluated to be about $0.4 \mathrm{~nm}$, where $P_{0}(q)$ is the scattering function of the chain contour. According to Nakamura and Norisuye, this plot has some certain linear region not only for straight rods but also wormlike chains. ${ }^{59}$ This small value may be reasonable because the chain thickness effect in $P(q)$ from SAXS reflects electron density profile of the chain cross section including solvent molecules. ${ }^{43,60-61}$ We therefore analyzed the $P(q)$ data in terms of the thin wormlike chain with the following equation

$$
P(q)=\frac{2}{L^{2}} \int_{0}^{L}(L-t) I(q ; t) d t
$$

where $L$ and $I(q ; t)$ are the contour length and the characteristic function of the wormlike chain, respectively. It should be noted that the excluded-volume effects are negligible for the current $P(q)$ data because the Kuhn segment number is calculated to be 0.88 even for $\mathbf{P Q - 2 0 0}$, which is the highest molar mass sample to determine $P(q)$. We utilized the Nakamura-Norisuye expression for $I(q ; t) .{ }^{59,62}$ The theoretical $P(q)$ can be calculated for the required $M_{\mathrm{w}}$ with the Kuhn segment length $\lambda^{-1}$ and the helix pitch per residue $h$ (or the contour length per residue) which is related to $L$ as

$$
h=\frac{L M_{0}}{M_{\text {w }}}
$$


where $M_{0}$ denotes the molar mass of the repeat unit $\left(=300.2 \mathrm{~g} \mathrm{~mol}^{-1}\right)$. A curve fitting procedure was examined for the data to determine $h$. The resultant theoretical values well explain the experimental data except for the low- $q$ region for PQ-100 and PQ-200. This is most likely due to the larger molar mass component as described in the Experimental section. These features are also seen in the double logarithmic plots in Figure S9 in the supporting information. The parameter $h$ slightly decreased with lowering $M_{\mathrm{w}}$ and the value for PQ-20 was 17\% smaller than that for PQ200. This is likely because of the end effect. In this case, the contour length can be rewritten as

$$
L=\frac{M_{\mathrm{w}}}{M_{0}} h_{0}+\delta \text { or } h=h_{0}+\frac{M_{0}}{M_{\mathrm{w}}} \delta
$$

where $h_{0}$ and $\delta$ were the helix pitch per residue for infinitely long chain and difference in the contour lengths nearby the chain ends. Since good linearity of the plots of $h \mathrm{vs} M_{\mathrm{w}}{ }^{-1}$ as displayed in Figure 3(b) supports this suggestion, the two parameters were estimated to be $h_{0}=0.194 \mathrm{~nm}$ and $\delta=-0.80 \mathrm{~nm}$ from the line in the figure. This end effect might be due to the low electron density of side alkyl groups nearby the chain ends taking very small chain diameter $(0.4 \mathrm{~nm})$ into consideration. On the other hand, the chain stiffness only from the $P(q)$ data cannot be estimated because the theoretical dashed curve for the rigid rod fairly explains the experimental data including low- $q$ region. In any case, they are well explained by the theoretical solid red curves calculated for the wormlike chain with the above $h$ and $\lambda^{-1}=43 \mathrm{~nm}$ which was obtained from $\left\langle S^{2}\right\rangle_{\mathrm{z}}$ and $[\eta]$ described below. We should however consider that the parameter $h$ is significantly affected by the experimental error of $M_{\mathrm{w}}$. The above mentioned $M_{\mathrm{w}}$ dependent $h$ might be an artifact if the $M_{\mathrm{w}}$ values for low molar mass samples were overestimated by some reason such as slight optical anisotropy or molecular weight dependent $\partial n / \partial c$. Also, if it is due to the low electron density of both chain ends, $[\eta]$ should be free from the effect. We therefore analyzed the $\left\langle S^{2}\right\rangle_{z}$ and $[\eta]$ data both with and without taking the chain end effects into account as described below. 

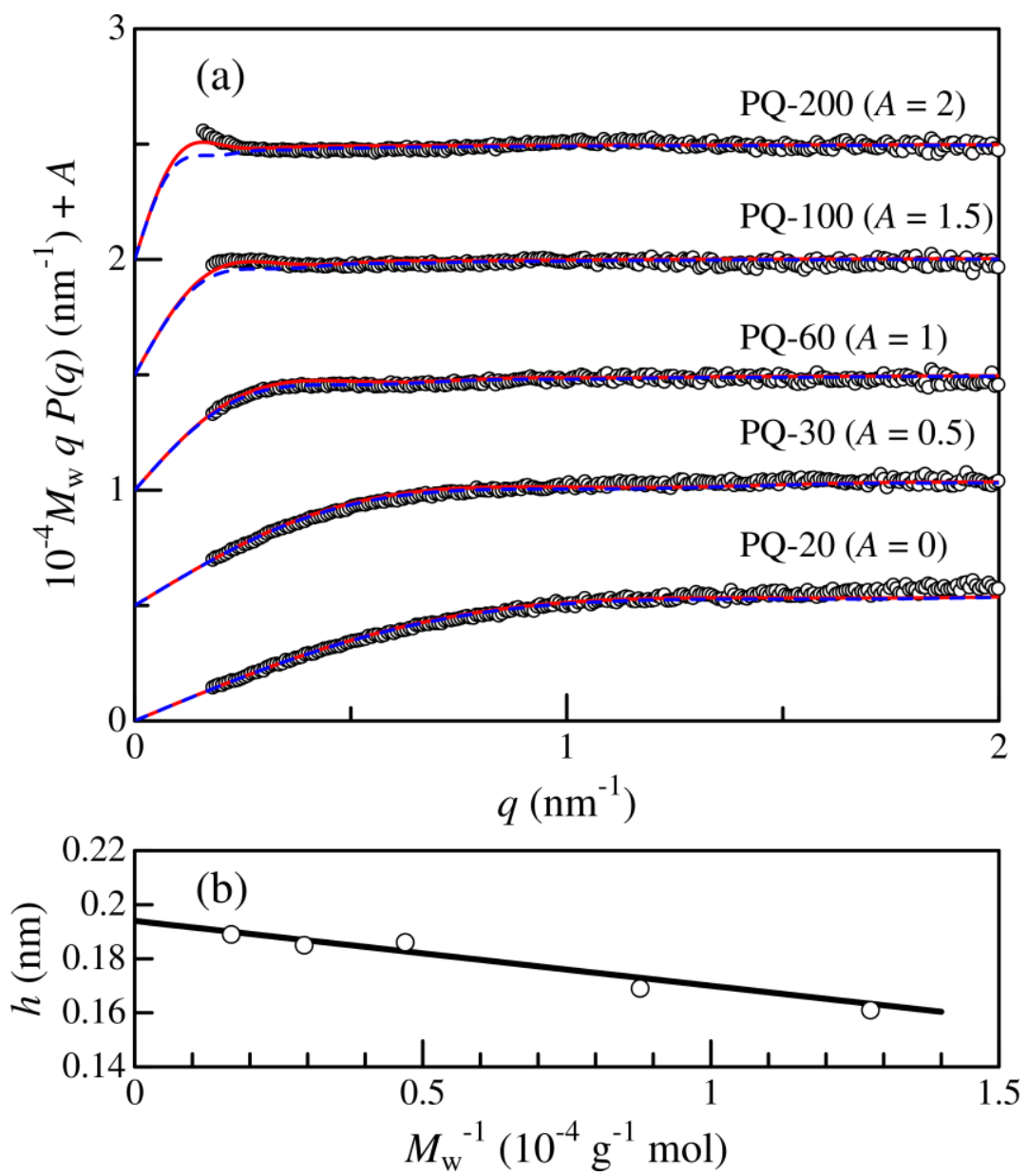

Figure 3. (a) Reduced Holtzer plots for indicated PQ-n samples in THF at $25^{\circ} \mathrm{C}$. Solid red curves and dashed blue curves denote the theoretical values for the wormlike chain and the rigid rod with the parameters in the main text. The ordinate values are shifted by $A$ for clarity. (b) Plots of $h$ vs $M_{\mathrm{w}}{ }^{-1}$ for PQ- $\boldsymbol{n}$ in THF at $25^{\circ} \mathrm{C}$.

The $M_{\mathrm{w}}$ dependence of $\left\langle S^{2}\right\rangle_{\mathrm{z}}$ is displayed in Figure 4. While the data points for three lower $M_{\mathrm{w}}$ samples are fitted by a straight dot-dashed line for the rigid rod with $h=0.184 \mathrm{~nm}$, those for the higher $M_{\mathrm{w}}$ samples are lower than the dot-dashed line. It is a typical feature for the wormlike chain having quite high chain stiffness. For the Kratky-Porod wormlike chain, the radius of gyration $\left\langle S^{2}\right\rangle$ can be calculated by the Benoit-Doty equation as ${ }^{63}$

$$
\left\langle S^{2}\right\rangle=\frac{L}{6 \lambda}-\frac{1}{4 \lambda^{2}}+\frac{1}{4 \lambda^{3} L}-\frac{1}{8 \lambda^{4} L^{2}}[1-\exp (-2 \lambda L)]
$$

If we choose $h=0.184 \mathrm{~nm}$ and $\lambda^{-1}=45 \pm 1 \mathrm{~nm}$, the solid curve quantitatively reproduces the experimental data. The Kuhn segment number $\lambda L$ for the highest $M_{\mathrm{w}}\left(=9.5 \times 10^{5}\right)$ fraction is 13.2 and hence the intramolecular excluded-volume effect is insignificant ${ }^{64-65}$ in terms of the quasi-twoparameter theory ${ }^{43,66-67}$ with the Domb-Barret equation. ${ }^{68}$ If we consider $M_{\mathrm{w}}$ dependent $h$ with eq 4 , slight smaller $\lambda^{-1}=42 \mathrm{~nm}$ was determined. The calculated dashed curve also reproduces the experimental data. 


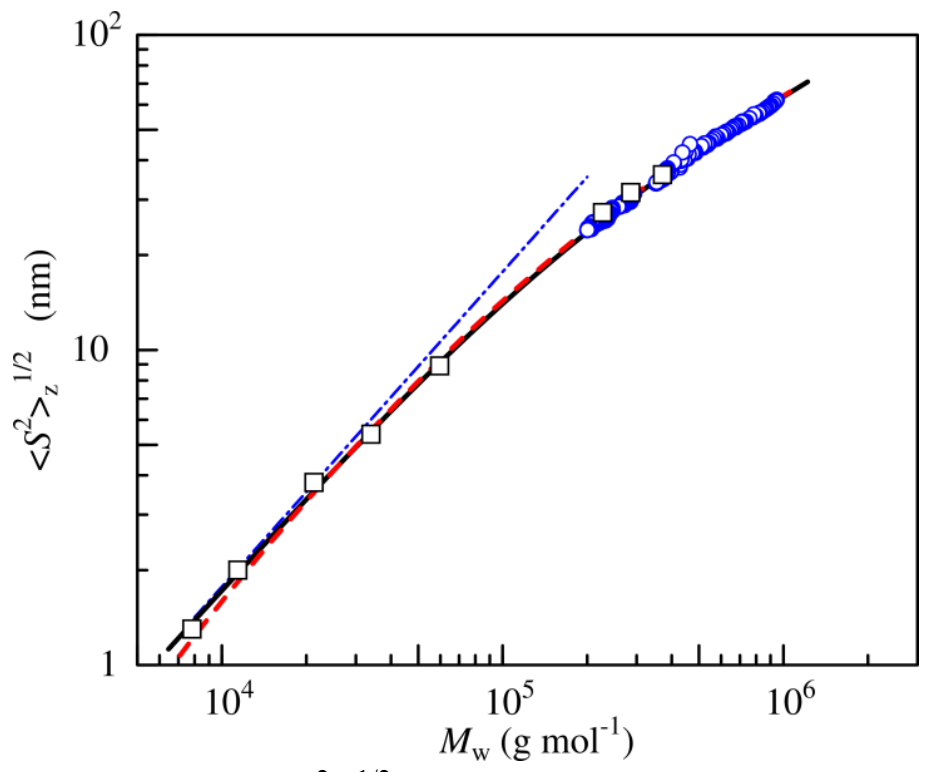

Figure 4. Double logarithmic plots of $\left\langle S^{2}\right\rangle_{\mathrm{z}}^{1 / 2}$ vs $M_{\mathrm{w}}$ for PQ- $\boldsymbol{n}$ samples in THF at room temperature. Squares, average values for each sample listed in Table 1; circles, data of each fraction from SEC. Solid and dashed curves indicate the theoretical values for the wormlike chain with fixed and $M_{\mathrm{w}}$ dependent $h$, respectively (see text). A dot-dashed line is for the rigid rod with $h=0.184 \mathrm{~nm}$.

Intrinsic viscosities $[\eta]$ for the PQ- $\boldsymbol{n}$ samples in THF are plotted against $M_{\mathrm{w}}$ in Figure 5. The Yamakawa-Fujii-Yoshizaki theory ${ }^{43,69-70}$ allows us to calculate $[\eta]$ for the wormlike cylinder with the three parameters of $h, \lambda^{-1}$, and the chain diameter $d$. Considering the end effects might affect $[\eta]$ for PQ-20 and PQ-30 as is the case with $P(q)$, the three parameters cannot uniquely be determined from the curve fitting procedure from the seven higher $M_{\mathrm{w}}$ samples. If we thus assume $h$ to be $0.186 \mathrm{~nm}$ which is the average value from $P(q)$ and $\left\langle S^{2}\right\rangle_{\mathrm{z}}$ for high $M_{\mathrm{w}}$ samples, the rest two parameters are estimated to be $\lambda^{-1}=45 \mathrm{~nm}$ and $d=2.3 \mathrm{~nm}$. The resultant theoretical values in Figure 5 are fitted by the experimental data including lower $M_{\mathrm{w}}$ samples. On the one hand, if we choose eq 4 for the parameter $L$, theoretical values calculated with slightly different parameters, $\lambda^{-1}=40 \mathrm{~nm}$ and $d=2.6 \mathrm{~nm}$, also reproduce the experimental data. These parameters are summarized in Table 2. Not significant difference were found both for the chain stiffness and the chain diameter from the two methods. Consequently, we may conclude that the wormlike chain parameters of poly[5,8-dimethyl-6,7-bis(propoxymethyl)quinoxaline-2,3-diyl] are as follows: $h=$ $0.19 \mathrm{~nm}, \lambda^{-1}=43 \pm 3 \mathrm{~nm}$, and $d=2.4 \pm 0.2 \mathrm{~nm}$. 


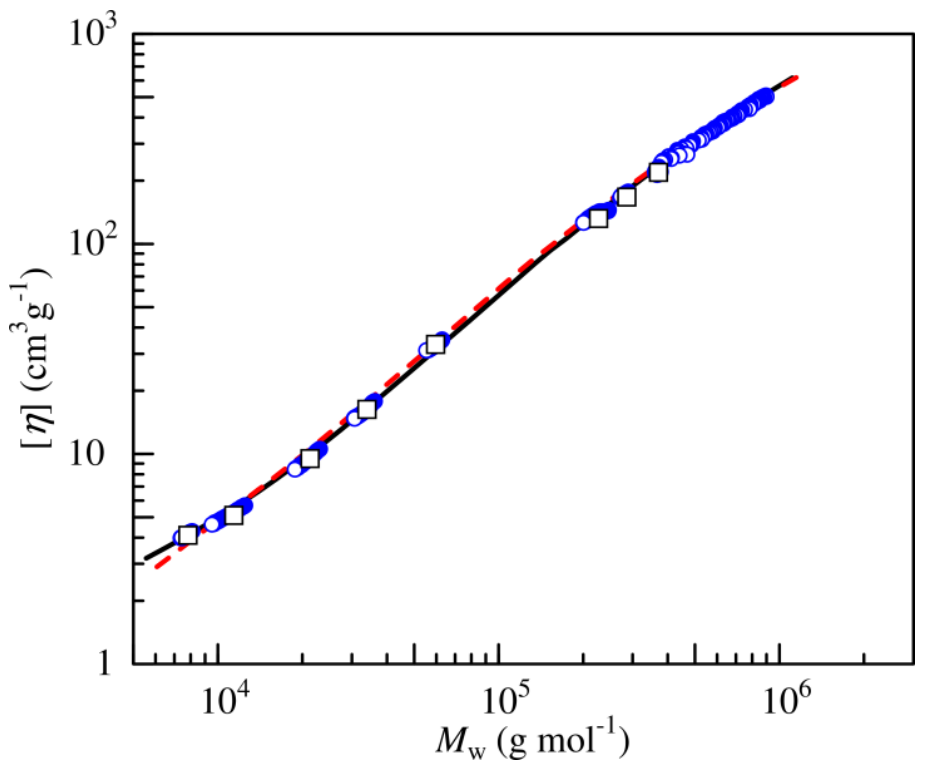

Figure 5. Double logarithmic plots of [ $\eta]$ vs $M_{\mathrm{w}}$ for PQ-n samples in THF at room temperature. Squares, average values listed in Table 1; circles, data of each fraction from SEC. A solid and dashed curves indicate the theoretical values for the wormlike chain with fixed and $M_{\mathrm{w}}$ dependent $h$, respectively.

Table 2. Wormlike Chain Parameters of poly[5,8-dimethyl-6,7bis(propoxymethyl)quinoxaline-2,3-diyl] in THF at $25^{\circ} \mathrm{C}$ or Room Temperature

\begin{tabular}{cccccc}
\hline Method & $h(\mathrm{~nm})$ & $h_{0}(\mathrm{~nm})$ & $\delta(\mathrm{nm})$ & $\lambda^{-1}(\mathrm{~nm})$ & $d(\mathrm{~nm})^{\mathrm{b}}$ \\
\hline Fixed $h$ & $0.186 \pm 0.003^{\mathrm{a}}$ & & & $44 \pm 2$ & 2.3 \\
$M_{\mathrm{W}}$ dependent $h$ & & $0.194 \pm 0.002$ & $-0.8 \pm 0.02$ & $41 \pm 2$ & 2.6 \\
\hline
\end{tabular}

${ }^{\mathrm{a}}$ Except for PQ-20 and PQ-30. ${ }^{\mathrm{b}}$ From $[\eta]$.

As mentioned in the Introduction, the helix pitch per residue $h$ is related with the helical structure. In a previous paper, ${ }^{29}$ the authors carried out the calculation of 20 -mers with fixed dihedral angle $\psi\left(=0^{\circ}\right)$ to reduce computational complexity, and a minimum of the total energy was observed at $\phi=135^{\circ}$. In this study, the total energy of quinoxaline 20-mers was calculated by varying the dihedral angle $\phi$, between two adjacent quinoxaline units from 40 to $140^{\circ}$ with an interval of $5^{\circ}$, along with optimizations of the dihedral angle $\psi$, bond lengths, and other angles by the semi-empirical molecular orbital method (MOPAC PM6). For a fixed internal rotation angle, this $h$ value can be obtained as a function of $\phi$ as shown in Figure 6 in which $h=0.19 \mathrm{~nm}$ corresponds to $\phi=120^{\circ}$. If we assume the evaluation error of $h$ to be $\pm 0.005 \mathrm{~nm}$, the resultant range of the dihedral angle between $113^{\circ}$ and $130^{\circ}$. It is fairly consistent with that for minimum of the internal rotation potential. Thus, PQ- $\boldsymbol{n}$ has a rather extended helical conformation in THF as illustrated in Figure 7a. In sharp contrast, it was reported that helical conformations of poly $(o-$ phenylene)s are rather similar to Figure $7 \mathrm{~b}$ based on the single crystal X-Ray diffraction for the model oligomer and NMR measurements. ${ }^{71}$ The characteristic feature of PQXs may be attributed to the unique helical conformation in dilute solution. 

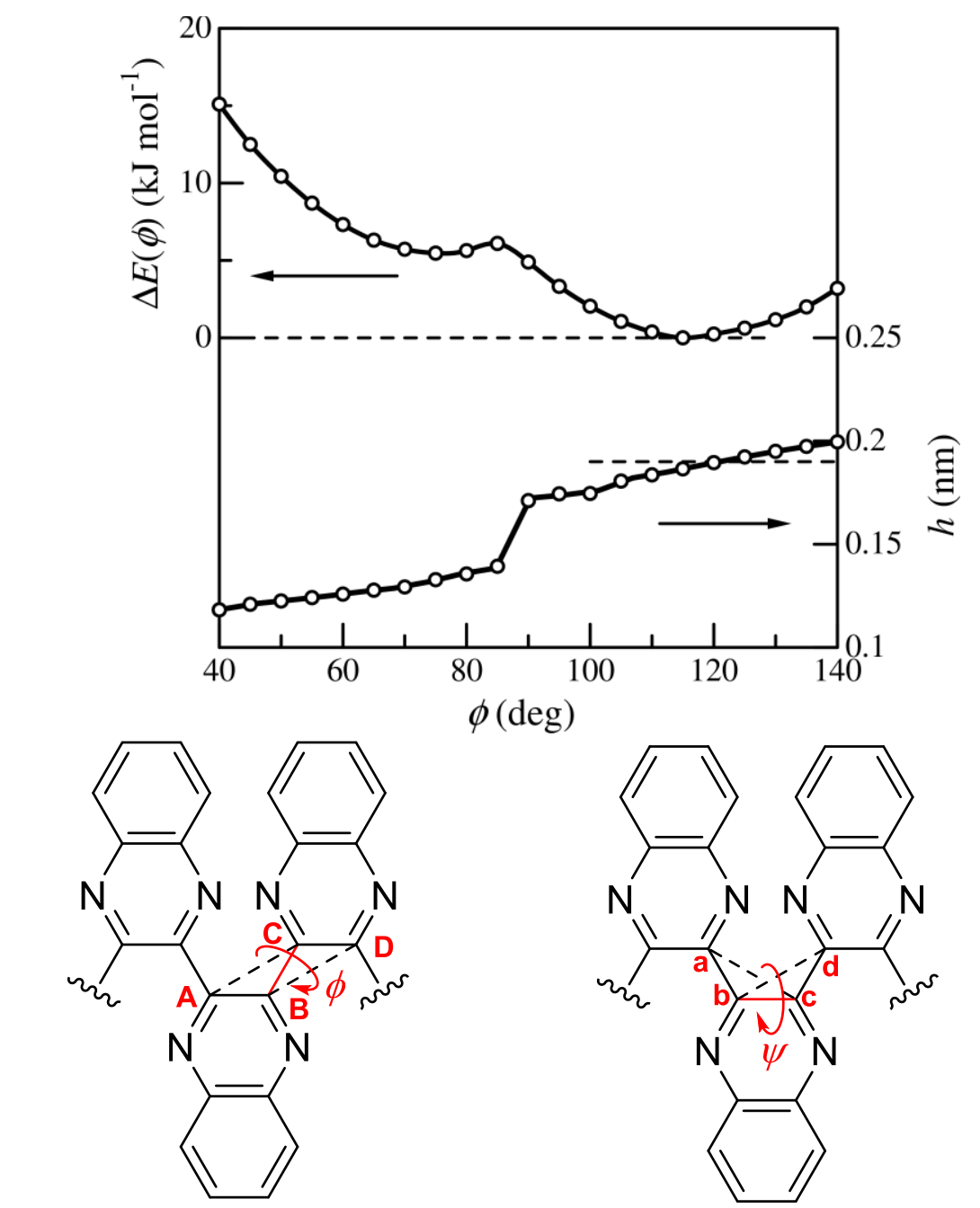

$\phi:$ dihedral angle between

$\psi:$ dihedral angle between

A-B-C and B-C-D

$a-b-c$ and $b-c-d$

Figure 6. Dependence of the excess internal rotation potential $\Delta E(\phi)$ and $h$ on dihedral angle $\phi$ for poly[5,6,7,8-tetramethylquinoxaline-2,3-diyl] (20-mer). Dihedral angle $\psi$, bond lengths, and other angles were optimized by the semi-empirical molecular orbital method. 

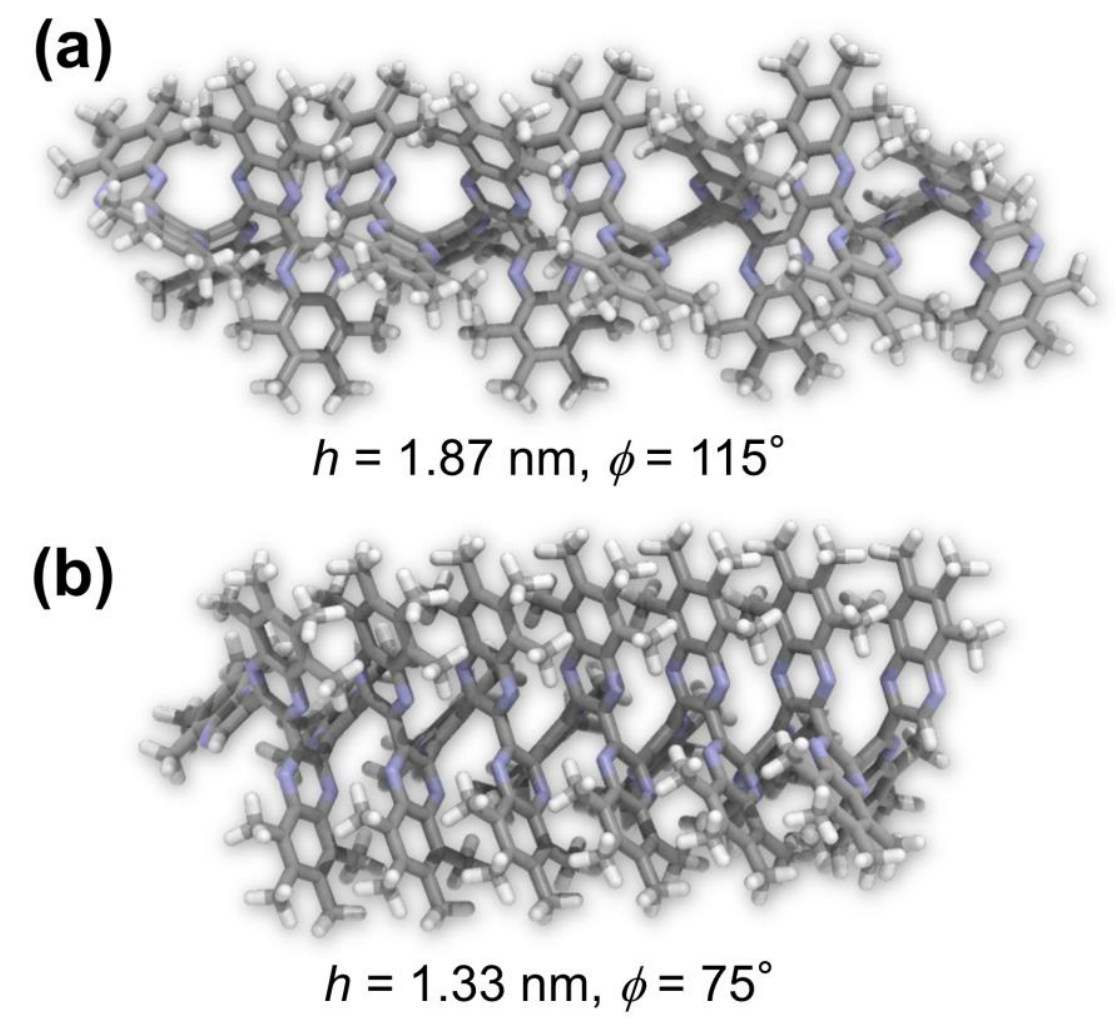

Figure 7. Plausible helical conformations of PQXs with dihedral angles (a) $\phi=115^{\circ}$ and (b) $\phi=$ $75^{\circ}$. Alkoxy side chains were omitted for clarity.

The determined chain stiffness of $43 \mathrm{~nm}$ is close to typical semiflexible polymers, such as poly $\left(n\right.$-hexylisocyanate) $\left(\lambda^{-1}=42-84 \mathrm{~nm}\right.$ depending on solvent $),{ }^{56,72-73}$ but somewhat shorter than those for $\alpha$-helical polypeptides. ${ }^{74-75}$ However, the chain stiffness of semiflexible polymers may be affected significantly by the side group and interactions with solvent molecules. For example, $\lambda^{-1}$ values for polyisocyanates are reported to be from $6 \mathrm{~nm}$ to $84 \mathrm{~nm},{ }^{21}$ those for polysilanes are between $2 \mathrm{~nm}$ and $210 \mathrm{~nm},{ }^{76-77}$ and those for amylose carbamate derivatives from $9 \mathrm{~nm}$ to $75 \mathrm{~nm} \cdot{ }^{25,27,78}$ Furthermore, according to Sato et al, ${ }^{18,79}$ the chain stiffness may also be affected by the helix reversal for some helical polymers. Thus, investigation of PQXs consisting of optically active side groups would allow elucidation of the origin of the chain stiffness.

\section{Conclusions}

We determined the helix pitch per residue of $0.19 \mathrm{~nm}$ and the Kuhn segment length of $43 \pm 3$ $\mathrm{nm}$ for poly[5,8-dimethyl-6,7-bis(propoxymethyl)quinoxaline-2,3-diyl] in THF at room temperature, indicating this polymer behaves as typical semiflexible polymer in solution. The former parameter is consistent with one of the helical conformation predicted by the semiempirical molecular orbital method, suggesting that the PQXs has helically aligned quinoxaline rings with the dihedral angle $\phi=113^{\circ}$ to $130^{\circ}$ in dilute solution. Although helical conformations of $\operatorname{poly}(o$-arene $) \mathrm{s}$ such as poly $(o$-phenylene $) \mathrm{s},{ }^{71,80-82} \operatorname{poly}(o$-naphthylene $) \mathrm{s}^{83-84}$ and $\operatorname{poly}(o-$ quinoline $) \mathrm{s}^{85}$ are attracting much interest, methods for the elucidation of the conformation of poly $(o$-arene $)$ s is still limited to single crystal X-ray diffraction for the oligomeric model compound and NMR measurement. We believe that an approach using light or X-ray scattering measurements of polymer solutions in combination with the theoretical calculations in 
conformational analysis can provide powerful tools to reveal their helical conformations in dilute solutions.

\section{Supporting Information}

Additional experimental procedures, ${ }^{1} \mathrm{H}$ NMR spectra, and additional plots for the SAXS data. This material is available free of charge via the Internet at http://pubs.acs.org.

\section{Notes}

The authors declare no competing financial interest.

\section{Acknowledgments}

The authors thank Prof. Takahiro Sato in Osaka University for valuable discussions and Dr. Noriyuki Igarashi in KEK for SAXS measurements. The synchrotron radiation experiments were performed at the BL-10C in KEK-PF under the approval of the Photon Factory Program Advisory Committee (No. 2013G516) and at the BL40B2 in SPring-8 with the approval of the Japan Synchrotron Radiation Research Institute (JASRI) (Proposal No. 2014B1087). This work was partially supported by JSPS KAKENHI Grant No. 25410130.

\section{References}

(1) Cheng, R. P.; Gellman, S. H.; DeGrado, W. F. Chem. Rev. 2001, 101, 3219-3232.

(2) Cornelissen, J. J.; Rowan, A. E.; Nolte, R. J.; Sommerdijk, N. A. Chem. Rev. 2001, 101, 4039-4070.

(3) Hill, D. J.; Mio, M. J.; Prince, R. B.; Hughes, T. S.; Moore, J. S. Chem. Rev. 2001, 101, 3893-4012.

(4) Nakano, T.; Okamoto, Y. Chem. Rev. 2001, 101, 4013-4038.

(5) Yashima, E.; Maeda, K.; Nishimura, T. Chemistry 2004, 10, 42-51.

(6) Yashima, E.; Maeda, K.; Iida, H.; Furusho, Y.; Nagai, K. Chem. Rev. 2009, 109, 6102-

6211.

(7) Okamoto, Y.; Yashima, E. Angew. Chem. Int. Ed. 1998, 37, 1020-1043.

(8) Yashima, E. J. Chromatogr. A 2001, 906, 105-125.

(9) Shen, J.; Okamoto, Y. In Comprehensive Chirality; Carreira, E. M., Yamamoto, H., Eds.; Elsevier: Amsterdam, 2012, p 200-226.

(10) Reggelin, M.; Schultz, M.; Holbach, M. Angew. Chem. Int. Ed. 2002, 41, 1614-1617.

(11) Roelfes, G.; Feringa, B. L. Angew. Chem. Int. Ed. 2005, 44, 3230-3232.

(12) Watanabe, J.; Kamee, H.; Fujiki, M. Polym. J. 2001, 33, 495-497.

(13) Shopsowitz, K. E.; Qi, H.; Hamad, W. Y.; Maclachlan, M. J. Nature 2010, 468, 422-425.

(14) Khan, M. K.; Giese, M.; Yu, M.; Kelly, J. A.; Hamad, W. Y.; MacLachlan, M. J. Angew.

Chem. Int. Ed. 2013, 52, 8921-8924.

(15) Maxein, G.; Keller, H.; Novak, B. M.; Zentel, R. Adv. Mater. 1998, 10, 341-345.

(16) Maxein, G.; Mayer, S.; Zentel, R. Macromolecules 1999, 32, 5747-5754.

(17) Fujiki, M.; Koe, J. R.; Terao, K.; Sato, T.; Teramoto, A.; Watanabe, J. Polym. J. 2003, 35, 297-344.

(18) Sato, T.; Terao, K.; Teramoto, A.; Fujiki, M. Polymer 2003, 44, 5477-5495.

(19) Okoshi, K.; Sakurai, S.; Ohsawa, S.; Kumaki, J.; Yashima, E. Angew. Chem. Int. Ed.

2006, 45, 8173-8176. 
(20) Gu, H.; Nakamura, Y.; Sato, T.; Teramoto, A.; Green, M. M.; Andreola, C. Polymer 1999, 40, 849-856.

(21) Yoshiba, K.; Hama, R.; Teramoto, A.; Nakamura, N.; Maeda, K.; Okamoto, Y.; Sato, T. Macromolecules 2006, 39, 3435-3440.

(22) Okoshi, K.; Nagai, K.; Kajitani, T.; Sakurai, S. I.; Yashima, E. Macromolecules 2008, 41, $7752-7754$.

(23) Burchard, W. In Soft Matter Characterization; Borsali, R., Pecora, R., Eds.; Springer Netherlands: 2008, p 463-603.

(24) Tsuboi, A.; Norisuye, T.; Teramoto, A. Macromolecules 1996, 29, 3597-3602.

(25) Tsuda, M.; Terao, K.; Nakamura, Y.; Kita, Y.; Kitamura, S.; Sato, T. Macromolecules 2010, 43, 5779-5784.

(26) Ochiai, T.; Terao, K.; Nakamura, Y.; Yoshikawa, C.; Sato, T. Polymer 2012, 53, 39463950 .

(27) Terao, K.; Maeda, F.; Oyamada, K.; Ochiai, T.; Kitamura, S.; Sato, T. J. Phys. Chem. B 2012, 116, 12714-12720.

(28) Ito, Y.; Ihara, E.; Murakami, M.; Shiro, M. J. Am. Chem. Soc. 1990, 112, 6446-6447.

(29) Ito, Y.; Ihara, E.; Murakami, M.; Sisido, M. Macromolecules 1992, 25, 6810-6813.

(30) Ito, Y.; Miyake, T.; Hatano, S.; Shima, R.; Ohara, T.; Suginome, M. J. Am. Chem. Soc. 1998, 120, 11880-11893.

(31) Yamada, T.; Suginome, M. Macromolecules 2010, 43, 3999-4002.

(32) Ito, Y.; Ohara, T.; Shima, R.; Suginome, M. J. Am. Chem. Soc. 1996, 118, 9188-9189.

(33) Yamamoto, T.; Suginome, M. Angew. Chem. Int. Ed. 2009, 48, 539-542.

(34) Yamada, T.; Nagata, Y.; Suginome, M. Chem Commun (Camb) 2010, 46, 4914-4916.

(35) Nagata, Y.; Yamada, T.; Adachi, T.; Akai, Y.; Yamamoto, T.; Suginome, M. J. Am. Chem. Soc. 2013, 135, 10104-10113.

(36) Yamamoto, T.; Yamada, T.; Nagata, Y.; Suginome, M. J. Am. Chem. Soc. 2010, 132, 7899-7901.

(37) Yamamoto, T.; Akai, Y.; Nagata, Y.; Suginome, M. Angew. Chem. Int. Ed. 2011, 50, 8844-8847.

(38) Akai, Y.; Yamamoto, T.; Nagata, Y.; Ohmura, T.; Suginome, M. J. Am. Chem. Soc. 2012, 134, 11092-11095.

(39) Suginome, M.; Yamamoto, T.; Nagata, Y.; Yamada, T.; Akai, Y. Pure Appl. Chem. 2012, 84, 1759-1769.

(40) Nagata, Y.; Takagi, K.; Suginome, M. J. Am. Chem. Soc. 2014, 136, 9858-9861.

(41) Nagata, Y.; Nishikawa, T.; Suginome, M. Chem Commun (Camb) 2014, 50, 9951-9953.

(42) Kratky, O.; Porod, G. Recl. Trav. Chim. Pays-Bas 1949, 68, 1106-1122.

(43) Yamakawa, H. Helical Wormlike Chains in Polymer Solutions; Springer: Berlin, Germany, 1997.

(44) Yamakawa, H. Polym. J. 1999, 31, 109-119.

(45) Sato, T.; Teramoto, A. Adv Polym Sci 1996, 126, 85-161.

(46) Sato, T. Kobunshi Ronbunshu 2012, 69, 613-622.

(47) Ito, Y.; Ihara, E.; Uesaka, T.; Murakami, M. Macromolecules 1992, 25, 6711-6713.

(48) Carmona, E.; Paneque, M.; Poveda, M. L. Polyhedron 1989, 8, 285-291.

(49) Nagata, Y.; Ke, Y. Z.; Suginome, M. Chem. Lett. 2015, 44, 53-55.

(50) Terao, K.; Mays, J. W. Eur. Polym. J. 2004, 40, 1623-1627. 
(51) Terao, K.; Farmer, B. S.; Nakamura, Y.; Iatrou, H.; Hong, K. L.; Mays, J. W. Macromolecules 2005, 38, 1447-1450.

(52) Farmer, B. S.; Terao, K.; Mays, J. W. Int. J. Polym. Anal. Charact. 2006, 11, 3-19.

(53) Berry, G. C. J. Chem. Phys. 1966, 44, 4550-4564.

(54) Stewart, J. http://OpenMOPAC.net, 2007.

(55) Konishi, T.; Yoshizaki, T.; Yamakawa, H. Macromolecules 1991, 24, 5614-5622.

(56) Murakami, H.; Norisuye, T.; Fujita, H. Macromolecules 1980, 13, 345-352.

(57) Norisuye, T. Prog. Polym. Sci. 1993, 18, 543-584.

(58) Glatter, O.; Kratky, O. Small Angle X-ray Scattering; Academic Press: London, 1982.

(59) Nakamura, Y.; Norisuye, T. J. Polym. Sci., Part. B. Polym. Phys. 2004, 42, 1398-1407.

(60) Hickl, P.; Ballauff, M.; Scherf, U.; Mullen, K.; Linder, P. Macromolecules 1997, 30, $273-$

279.

(61) Arakawa, S.; Terao, K.; Kitamura, S.; Sato, T. Polym. Chem. 2012, 3, 472-478.

(62) Nakamura, Y.; Norisuye, T. In Soft Matter Characterization; Borsali, R., Pecora, R., Eds.; Springer Netherlands: 2008, p 235-286.

(63) Benoit, H.; Doty, P. J. Phys. Chem. 1953, 57, 958-963.

(64) Norisuye, T.; Fujita, H. Polym. J. 1982, 14, 143-147.

(65) Norisuye, T.; Tsuboi, A.; Teramoto, A. Polym. J. 1996, 28, 357-361.

(66) Yamakawa, H.; Stockmayer, W. H. J. Chem. Phys. 1972, 57, 2843-2854.

(67) Shimada, J.; Yamakawa, H. J. Chem. Phys. 1986, 85, 591-600.

(68) Domb, C.; Barrett, A. J. Polymer 1976, 17, 179-184.

(69) Yamakawa, H.; Fujii, M. Macromolecules 1974, 7, 128-135.

(70) Yamakawa, H.; Yoshizaki, T. Macromolecules 1980, 13, 633-643.

(71) Mathew, S.; Crandall, L. A.; Ziegler, C. J.; Hartley, C. S. J. Am. Chem. Soc. 2014, 136, 16666-16675.

(72) Kuwata, M.; Murakami, H.; Norisuye, T.; Fujita, H. Macromolecules 1984, 17, 27312734.

(73) Itou, T.; Chikiri, H.; Teramoto, A.; Aharoni, S. M. Polym. J. 1988, 20, 143-151.

(74) Itou, S.; Nishioka, N.; Norisuye, T.; Teramoto, A. Macromolecules 1981, 14, 904-909.

(75) Temyanko, E.; Russo, P. S.; Ricks, H. Macromolecules 2001, 34, 582-586.

(76) Teramoto, A.; Terao, K.; Terao, Y.; Nakamura, N.; Sato, T.; Fujiki, M. J. Am. Chem. Soc. 2001, 123, 12303-12310.

(77) Chung, W. J.; Shibaguchi, H.; Terao, K.; Fujiki, M.; Naito, M. Macromolecules 2011, 44, 6568-6573.

(78) Terao, K.; Murashima, M.; Sano, Y.; Arakawa, S.; Kitamura, S.; Norisuye, T. Macromolecules 2010, 43, 1061-1068.

(79) Sato, T.; Terao, K.; Teramoto, A.; Fujiki, M. Macromolecules 2002, 35, 2141-2148.

(80) Ohta, E.; Sato, H.; Ando, S.; Kosaka, A.; Fukushima, T.; Hashizume, D.; Yamasaki, M.; Hasegawa, K.; Muraoka, A.; Ushiyama, H.; Yamashita, K.; Aida, T. Nat. Chem. 2011, 3, 68-73. (81) Ando, S.; Ohta, E.; Kosaka, A.; Hashizume, D.; Koshino, H.; Fukushima, T.; Aida, T. $J$. Am. Chem. Soc. 2012, 134, 11084-11087.

(82) Mizukoshi, Y.; Mikami, K.; Uchiyama, M. J. Am. Chem. Soc. 2015, 137, 74-77.

(83) Motomura, T.; Nakamura, H.; Suginome, N.; Murakami, M.; Ito, Y. Bull. Chem. Soc. Jpn. 2005, 78, 142-146.

(84) Ito, S.; Takahashi, K.; Nozaki, K. J. Am. Chem. Soc. 2014, 136, 7547-7550.

(85) Suginome, M.; Noguchi, H.; Murakami, M. Chem. Lett. 2007, 36, 1036-1037. 
For Table of Contents Use Only

Main-Chain Stiffness and Helical Conformation of a Poly(quinoxaline-2,3-diyl) in Solution

Yuuya Nagata, Hirokazu Hasegawa, Ken Terao, and Michinori Suginome

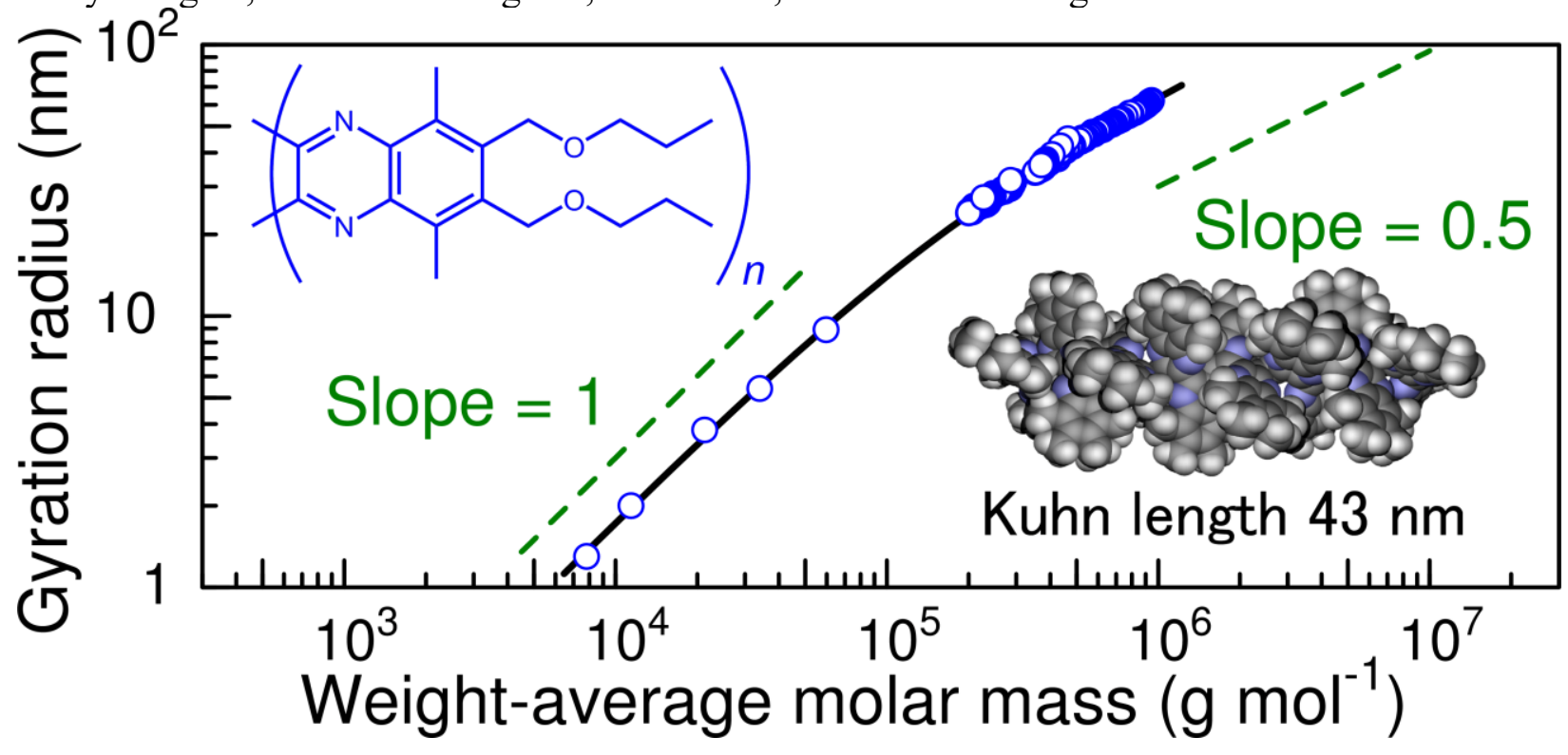

